\title{
PENGUCAPAN TALAK TIGA SEKALIGUS PERSEPSI ULAMA MUHAMMADIYAH KOTA PALANGKA RAYA
}

\author{
Ardi Akbar Tanjung ${ }^{1 *}$ Khairil Anwar ${ }^{2^{*}}$, Elvi Soeradji ${ }^{3^{*}}$ Muslimah ${ }^{4 *}$ \\ 1-4*Pascasarjana Insitut Agama Islam Negeri Palangka Raya
}

\begin{abstract}
Abstrak
Penelitian ini bermaksud untuk mengkaji lebih dalam tentang pengucapan talak sekaligus persepsi ulama Muhammadiyah Kota Palangka Raya dan dianalisis bagaimana kajian ulama Muhammadiyah melalui Al-quran, Hadits serta solusinya. Dilakukan dengan metode penelitian deskriftip kualitatif yaitu penelitian yang bermaksud menganalisis gambaran fenomena atau apa yang dialami mengenai suatu kenyataan sosial caranya dengan mendiskripsikansejumlah hasil data yang diteliti antara fenomena yang diujiguna untuk memperoleh pemahaman mendalam, mengembangkan teori, mendiskripsikanyang menelusuri referensi di dunialslam cetak maupun elektronik tentang pengucapan talak tiga sekaligus menurut persepsi ulamaMuhammadiyah Kota Palangka Raya melalui buku, journal, kitab suci Al-Qur'an serta beberapa hadist. hasil penelitian menyebutkan persepsi para Ulama Muhammadiyah Kota Palangka Raya bahwa orang yang menjatuhkan talak tiga hanya dihitung talak satu masih dan lebih relevan untuk kondisi masyarakat muslim untuk relevansi dengan kondisi sekarang dengan pertimbangan melalui perumusan Undang-Undang hukum positif islam yang berdasarkan hukum yang ada dan digunakan di Indonesia dalam hal ini kasus perceraian hanya bisa diproses dan diadili dalampersidangan Pengadilan Agama yang tertuangdidalam Undang-Undang Kompilasi Hukumlslam (KHI) pasal I I 5 "perceraian hanya dapat diputuskan di persidangan Pengadilan Agama dalam pasal II 5 yang berbunyi: Perceraian hanya dilakukan di depansidang Pengadilan Agama setelah Hakim sudah berusaha mendamaikan kedua belah pihak namun tidak berhasil" Kemudian dalam pasal 123 "perceraian akan berlaku pada saat setelah dinyatakan oleh Hakim persidangan.

Kata Kunci : Pengucapan Talak Tiga Sekaligus, Ulama Muhammadiyah Kota Palangka Raya
\end{abstract}

\begin{abstract}
This study intends to examine more deeply about Talak Pronunciation as well as Perceptions of Muhammadiyah Ulama in Palangka Raya City and to analyze how Muhammadiyah Ulama studies through Alquran, Hadith and their solutions. Conducted with a qualitative descriptive research method, namely research that intends to analyze a description of a phenomenon or what is experienced about a social reality by describing a number of data results that are researched between the participants who are tested in order to gain in-depth understanding, develop theories, describe tracing printed and electronic references about Talak Pronunciation at once according to Muhammadiyah Ulama Perception of Palangka Raya City through books, journals, the holy book of the Koran and several hadiths. The results of the study state the perception of the Muhammadiyah Ulama of Palangka Raya City that people who drop triple divorce are only counted as one talak and are more relevant to the condition of the Muslim community in the Islamic world for relevance to current conditions with consideration through the formulation of positive Islamic law laws based on existing laws. and used in Indonesia, in this case, divorce cases can only be processed and tried in the Religious Courts trial as stated in the Law Compilation of Islamic Law (KHI) article II5 "Divorce can only be decided in trials at the Religious Courts in article II5 which reads: Divorce can only be done before the trial of the Religious Court after the Judge has tried to reconcile the two parties but was unsuccessful "Then in article 123" the divorce will take effect when it is declared by the trial Judge.
\end{abstract}

Keyword : Talak Pronunciation at once, MuhammadiyahUlamaPalangka Raya City 


\section{PENDAHULUAN}

Melakukan sebuah perkawinan yang dianjurkan oleh umat Islam,di sisilainmembolehkan hubungan lawan antara laki-laki dan perempuan lawan jenis adalah bagian dari sunah Nabi Muhammad SAW, terwujudnya keinginan tersebut tergantung pada kuatnya hubungan antara suami dan istri itu jika mereka bisa dengan benar melaksanakan keutuhannya sebagai pasangan yang ideal Sulaiman Rasyid: 20II).Namun dalam menjalani keutuhan keluarga tentu adakalanya tidak terus-menerus seusai dengan yang di inginkan, terkadang timbul waktu dan keadaan di mana mereka hampir tidak bisa memegang teguh perkawinannya. Sehingga pengucapan talak berlaku dalam ajaran umat Islam sebagai titik terang keluar dari berbagai permasalahan berat di dalamberumah tangga pada pasangan antara suami dan istri,di mana jika tidak dilakukan perceraian maka akan mendapat kemudharatan atau bahaya dari salah satu pasangan tersebut. Dengan istilah lain berlakunya talak apabila suami istri tidak dapat menjalankan kewajibannya sehingga menimbulkan dampak yang bahaya besar ketika dalam membangun dan menjalankan keluarga.

Ibnu Taimiyah telah berpendapat tentang talak tiga sekaligus bahwa talak tersebut tidak terjadi talak tiga tapi hanya jatuh talak satu. Dalam menguatkan pendapatnya, Ibnu Taimiyah kembali menggali dalam ayat suci Al-Qur'an Ibnu Taimiyah memahami Q.S. al-Baqarah:229, khususnya pada lafal (marratani) yang sebenarnya menunjukan (dilalah) kepada talak raj'i. Menurut Ibnu Taimiyah hal tersebut sebenarnya menunjukan bahwa talak tersebut mesti dilakukan dengan tahapan dan di waktu yang tidak sama. Sebagaimana yang diungkapakannya dalam pemikiran Ibnu Taimiyah sebelumnya bahwa selain secara bertahap juga setelah habis masa idahnya. Apabila talak tersebut dilakukan secara bertahap dan pada waktu yang berbeda, namun idahnya belum selesai, maka ini pun dikatakan talak haram atau bid'ah. Terlebih lagi bila diucapkan secara sekaligus. Kemudian menurut Hasbi ash-Shiddieqi yang mengatakan bahwa perceraian itu mesti dimulai secara bertahap, bukan langsung jatuh perceraian. Adanya persyari'atan seperti ini adalah agar bekas laki-laki dapat melakukan berkumpul lagi pada bekas perempuan yang diceraikannya. Mayoritas para pakar hukum islam (fikih) pun, lanjutnya, menyepakati bahwa talak syar'i atau disebut sesuai syari'at adalah talak yang dijatuhkan satu kali satu kali. Makna yang tepat untuk lafal "marratani" itu adalah sekali sesudah sekali (satu satu). Oleh karena itu menurut Hasbi, menjatuhkan talak secara sekaligus hukumnya bid'ah dan haram (Hasbi ash-Shiddieqy : 2000).

Sedangkan persepsi atau sikap pada menjatuhkancerai dengan ucapan secara langsung hingga terjadinya perceraian dan tidak bisa rujuk kembali adalah persepsi para imam seperti Imam Hanafi, Imam Maliki, Imam Syafi'i dan Imam Hambali dan Syi'ah Zaidiyah pada persepsi yang mashur, bahkan persepsi Ibnu Hazm Az-Zhahiri. Persepsi ini dikutip daripersepsi para tabi'in, kecuali Khalifah Abu Bakar Ash-Siddiq, Ibnu Abbas, Ibnu Mas'ud, Abu Hurairah, sertapara tokoh tabi'in waktu zamanNabiMuhammad SAW serta pada zaman Khalifah Abu Bakar AshShiddiq talak diberlakukan hukunya talak 3 (tiga) terhitung tetap I (satu). Dalam artian talak 2(dua) akan dianggap sah jika suami telah rujuk kemudian kembali selesai dia melakukan talak. Tetapi pada zaman Khalifah Umar bin Khattab, masih terdapat laki-laki telah mempermainkan perceraian. Maka hal tersebut talak yang di berlakukan langsung 3 (tiga) tetap hukumnya 3 (tiga), maka sebab pemberlakuan adanya talak karena ingin memberikan sanksi terhadap orang-orang yang melanggar ketentuan dari Allah SWT dalam masalah talak amir Syarifudin: 2006). Kemudian pendapat murid-murid Ibnu 'Abbâs RA di antaranya 'Atha', Sa'îd bin Jubair, Abûs Sya'tsâ', 'Amar bin Dînâr, yang merupakan mazhab Ishâq bin Râhawiyah yang menafsil (memerinci), yakni memisahkan antara istri yang sudah digauli oleh suami yang menalaknya dan istri yang belum digauli oleh suaminya. Talak tiga yang diucapkan sekaligus terhadap istri yang sudah digaulinya, maka jatuh talak tiga, tetapi terhadap istri yang 
belum digaulinya, maka jatuh talak satu (talak raj'i dalilnya antara lain, HR Abû Dâwud: "apabila sesorang telah menalak istrinya dengan jumlah 3 (tiga) kali sebelum mereka melakukan hubungan badan maka hal itu menjadikan hukumnya tetap jatuh talak I (satu) (Jedah, Maktabah Al-Irsyâd: 1999).

Menanggapi permasalahan diatas, maka peneliti tertarik melakukan kajian lebih dalam tentang pengucapan alak tiga sekaligus persepsi ulama Muhammadiyah Kota Palangka Raya, dan yang masih terjadi perbedaan pendapat (Ikhtilaf)di antara para ulama Fikih mengandung pertanyaan adalah bagaimana status hukum menjatuhkan talak tiga secara sekaligus atau dalam satu kali ucapan. Dalam bahasa lain dikatakan bagaimana status hukum orang yang menjatuhkan talak ketiga bersamaan dengan talak satu dan dua sekaligus ketika pertama kali mengucapkan talak dan bagaimana relevansinya dengan kondisi zaman sekarang khususnya di Indonesia.

\section{METODE PENELITIAN}

Pelaksanaan penelitian ini metode atau cara yang dilaksanakan menggunakan metode kualitatif yakni suatu cara yang dilakukan dengan memfokuskan proses pencarian data yang berkualitas sesuai dengan yang diperlukan (Muslimah, dkk: 2020). Adapun sifat penelitian ini adalah deskriptif yakni apayang sudah disampaikan oleh narasumber baik persepsi atau pandangan dan sikap dari ulama Muhammadiyah Kota Palangka Raya yang ada pada penelitian dan dipahami secara menyeluruh yang kemudian di gambarkan atau dalam bentuk hasil penelitian untuk menjawab masalah yang telah dirumuskan bersifat deskriptif dimaksudkan adalah supaya peneliti dapat mengetahui dan menggambarkan hal-hal yang terjadi dilokasi penelitian dan berusaha mengungkapkan data tentang peengucapan talak tiga sekaligus menurut ulamahammadiyah Palangka Raya.

Dengan demikian yang diharapkan dari peneliti adalah untuk mengetahui dan mendeskripsikan para ulama Muhammadiyah Kota Palangka Raya terhadap pengucapan talak tiga sekaligus dan alasan yang dijadikan dasar oleh para ulama dalam memberikan pernyataan tentang status hukum pengucapan talak tiga sekaligus. Menggali informasi tentang data yang diperlukan maka penulis menggali data dari 5 (lima) ulama Muhammmadiyah Palangka Raya yang dalam hal ini mereka berlaku sebagai subjek penelitianmenggali data melalui badan tarjih dan tajdid muhammadiyah.

\section{PEMBAHASAN DAN HASIL PENELITIAN}

\section{A. Pengertian Talak}

Sebelum membahas permasalahan dari kajian ini, terlebih dulu penulis sampaikan definisi kata "talak"talak secara bahasa berarti melepaskan ikatan. Dengan kata lain, talak adalah memutuskan hubungan antara suam iistri dari ikatan pernikahan yang sah menurut syariat agama. Meski demikian, Islam juga memperbolehkan adanya rujuk setelah suami menjatuhkan talak pada istrinya, tapi tetap dengan beberapa catatan yang menjadi alasan dasar hokum talak terdapat dalam ayat suci Al-quran Allah berfirman:

"Talak (yang dapat dirujuk) itu dua kali. (Setelah itu suami dapat) menahan dengan baik, atau melepaskan dengan baik. Tidak halal bagi kamu mengambil kembali sesuatu yang telah kamu berikan kepada mereka, kecuali keduanya (suami dan istri) khawatir tidak mampu menjalankan hukum-hukum Allah. Jika kamu (wali) khawatir bahwa keduanya tidak mampu menjalankan hukum-hukum Allah, maka keduanya tidak berdosa atas bayaran yang (harus) diberikan (oleh istri) untuk menebus dirinya. Itulah hukum-hukum Allah, maka janganlah kamu melanggarnya. Barangsiapa melanggar hukumhukum Allah, mereka itulah orang-orang zalim" (QS. Al-baqarah : 228).

Dalam ayat ini disebutkan lafal marratani" itu adalah satu sesudah satu sebagaimana apabila ada orang berkata: beryasbihlah dua kali, atau tiga kali atau seratus kali. Sudah pasti bahwa yang dimaksudkan disitu adalah membaca tasbih seperti "subhanallah, sampai semprnanya bilangan yang ditentukan. Bertasbih itu tidak bisa terjadi itu kecuali sekali dan Allah sendiri tidak berfirman talak adalah dua kali talak.

Kompilasi Hukum Islam (KHI) secara resmi sejak tahun 1991 di jadikan sebagai pedoman dalam peradilan agama di Indonesia mengatur ketentuan-ketentuan yang berkaitan dengan rumah tangga keluarga muslim. Khususnya berkaitan dengan putusnya perkawinan (talak) ini, terhadap Undang-Undang Kompilasi Hukum Islam $(\mathrm{KHI})$ juga telah disusun padaBab 6 (enambelas) terkait putusnya pernikahan.. 
Pengertian talak secara langsung atau sekaligus yaitu apabila seorang suami telah melafazdkannya terhadap istrinya dengan saya talak kamu secara sekaligus 3 (tiga)atau dengan lafadz aku talak kamu, aku talak kamu aku talak kamu dengan jumlah 3 (tiga) kali. Permaslahannya adalah jika suami menyatakan hal tersebut, akankah istrinya tersebut mendapatkan talak satusaja atau langsung talak tiga Dalam hal ini kalau memang dikatakan berlakunya talak satu maka suami berhak untuk kembali rujuk dikarenakan lelaki yang merdeka punya tiga langan talak,dan si laki-laki tidak berhak untuk kembali rujuk. Begitu pula si perempuan apabila berkawin dengan orang lain selain mantan suaminya tersebut. kemudian meneruskan kehidupan rumah tanggasebagaimana biasa dengan suami barunya, $\mathrm{k}$ emudian selang tempo masa si suami barunya menceraikan perempuan tersebut, barulah si suami pertama tadi dapat mengawininya. Jelasnya persoalan itu walau pun dilihat kecil tapi mempunyai implikasi hukum yang cukup besar pada suami isteri berkenaan. Sementara itu talak tiga sekaligus sama dengan talak ba'inkubra yaitu talak tiga dan istri tidak menjadi halal lagi bagi mantan suaminya. lika ingin rujuk, mantan istriya menikah dengan laki-laki lain terlebih dahulu.

Beberapa hadits yang menyebutkan tentang talak tiga sekaligus sebagai berikut:

"Ibnu Abbas menyatakandahulu Talak ketika masa Nabi Muhammad SAW dan Masa Khalifah Abu BakarAsh-Shiddiq serta 2 (dua) tahun pada masa pemerntahan Khalifah Umar Bin Khattab, permbakuan Talak secara langsung atau 3 (tiga) hanya terhitung talak I(satu) Maka Khalifah Umar Bin Khattab bahwa apabila terdapat orang-orang yang terlalu cepat dalam membuat sebuah ketetapan terhadap suatu masalah maka akan cenderung menyulitkan golongan itu sendiri namun kami jalankan, maka akan saya terapkan kepada golongan tersebut (yakni talak tiga memang jatuh talak tiga) (H.R. Muslim).

Dari pernyataan Hadits tersebut menandaskan bahwa terjadinya talak pada waktu itu memberikan ruang agar bisa kembali rujuk, jadi tidak akan bisa segara berlaku 3 (tiga) kali talak dan ditiadakan sekalipun rujuk, namun karena pada masa itu sering sekali terjadinya talak hanya dengan sekali ucapan talak 3 (tiga) sekaligus, maka Khalifah Umar Bin khattab memberlakukan talak sekali ucapan jatuh hukumnya talak 3 (tiga) sekaligus di karenakan ini dilaksanakan serta merta agar masyarakat pada masa pemerintahan umar tidak dengan mudah mengucapkan talak secara langsung. Tetapi masih ada kesempatan untuk pasangan tersebut rujuk

"Pada Masa Nabi Muhammad SAW dikasih tau bahwa ada seorang laki-laki yang sudah menalak istrinya tersebut dengan hukuman jatuh talak 3(tiga) atau secara langsung dalam satu lafadz, lalu beliau berdiri dengan keadaan emosi dan berkata "Apakah ia ingin bermain-main dengan Kitabullah padahal aku masih ada di tengah kalian.?" Pada waktu itu ada seseorang laki-laki tersebut juga berdiri dan bertanya "Wahai Rasulullah, bolehkah aku membunuhnya.?"

Nabi Muhammad SAW emosi ketika mendengarahwa laki-laki itu sudah menalak istrinya dengan hukuman jatuh talak 3 (tiga) sekaligus, emosinya Nabi pada saat itu menandakan bahwa talak itu hukumnya 3 (tiga) sekaligus dikarenakan jika hukunya tidak sekaligus dan hanya berlaku talak I (satu), tentunya marahnya Nabi pada saat itu tidak ada manfaat atau hikmahnya. Dalam hal tersebut juga ada pada hadits Nabi Muhammad SAW "Perbuatan yang mubah yang dimarahi Tuhan adalah talaq". Namun hukumnya tetap sah jatuh talak. Dalam hal itu, emosinya Nabi tersebut ingin menyampaikan kepada semua orang bahwa perbuatan hal tersebut merupakan perbuatan yang sangat keji dan tidak disukai Nabi Muhammad SAW.

Mengenai Hadis diatas dan yang berpendapat diantara tokoh muslim perihal perkara tersebut, tidak serta merta dikarenakan ada beberapa referensi bukubuku yang bertolak belakang perihal perkara ini, tetapi karena adanya perbedaan pendapat dalam mengartikan referensi dan buku-buku tersebut. adapun pemahaman yang mengartikan bahwa terhitung talak secara langsung selafadz pemahaman ini dibenarkan para sebagian tokoh ulama diantaranya 4 (empat) Imam Mazhab serta Az- Zahiriyah dan sebagian besar sahabat di antaranya Khulafaurrrasyidin selain Abu Bakar ra, Abu Hurairah dan sebagian besar tabi'in. Adapun persepsi lain mengatakan Talak dengan lafadz 3 (tiga) langsung hukumnya tetap I (satu). Persepsi tersebut di benarkan oleh tokoh 
bernama Az-Zaidiyah, Zhahiriyah, Abu Ishaq, Ibnu Taimiyah, serta Ibnu Qayyim. Berdasarkan kitab suciAl-Quran serta dari hadis diatas, Ibnu Taimiyah menyatakan bahwa sebagaimana dalam Al-Quran dan Hadits belum ada mewajibkan yang memberlakukan 3 (tiga) talak kepada mereka yang telah mensahkan talak tersebut sekliagus atau jatuh talak 3 (tiga) hanya dengan satu lafadz atau satu waktu. Dengan meniadakan adanya rujuk dan akad. Dari pandangan Ibnu Taimiyah dan para ulama lain sepakat bahwa talak hanya rukhsah atau tidak sah hukumnya. Karena pengucapan talak tersebut awalnya diharamkan dan tidak benarkan oleh Allah SWT, dengan satu kali dan waktu yang sama dan jumlah angka talak. Dalam Al-Quran sudah mengartikan nominal talak bahwa talak terjadi 3 (tiga) kali dengan melakukan dan penerapannya dengan secara bertahap tidak secara langsung. Dalam arti lain bahwa, apabila seorang suami melakukan pernikahan dengan seorang perempuan, kemudian terjadi perselisihan hingga mengakibatkan laki-laki menalak istrinya tersebut maka jatuhlah talaknya tetapi hanya berlaku pertama atau I (satu) kali, lalu baru terhitung kedua kali setelah melakukan talak satu sebelumnya dengan waktu yang berbeda, sang suami sudah rujuk terhadap istrinya (selagi saat waktu iddah) bisa juga kawin lagu apabila saat atau waktu Iddahnya selesai. Begitulah berlakunya hukum talak yang ke 3 (tiga), ialah ia akan diakui apabila ada sesudah berlakunya talak 2 (dua) suami kembali lagi ke istrinya atau suami menikahi lagi di sebabkan sudah selesai waktu Iddahlalu menalaknya. di sebabkan dalam kitab suci Al-Quran telah membuat tentang hukum talak yang awalnya dalah diharamkan itu, maka sebagaimana yang dimaksud hukum berlakunya 3(tiga) talak secara langsung atau sekaligus termasuk kepada hal yang diharamkan tergolong dalam jenis perbuatan yang tidak dibenarkan, dan melaksanakan perilaku yang tidak dibenarkan maka hukum tersebut ialah batil.

\section{B. Persepsi Ulama Muhammadiyah Tentang Pengucapan Talak Tiga Sekaligus}

Dari hasil penelitian oleh peneliti bahwasannya pengucapan talak tiga sekaligus persepsi 5 (lima) ulama Muhammadiyah Kota Palangka Rayasebagai beriku:

Subjek I YM: bahwa sebagai ulama Muhammadiyah tentang status hukum pengucapan talak tiga sekaligus mengacu kepada Al-Quran dan Hadits, memang pada dasarnya pengucapan talak tiga sekaligus terjadi perbedaan pendapat namun sudah sangat jelas dalam Al-Quran surah AlBaqarah:229 mengatakan talak itu dua kali, proses dua kali itu artinya ada tahapan sehingga dikatakan sempurna,apabila orang berucap tiga kali itu harus dilihat apakah saat emosi atau marah jadi berdasarkan kesepakatan para ulama talak tiga sekaligus itu tidak ada tidak sah, pernah terjadi pada masa Khalifah Umar bin Khattab berpendapat bisa terjadi talak 3 (tiga) sekaligus dalam hal ini umar mengatakan untuk memberikan pelajaran pada orang orang itu dan tidak main main dengan masalah talak.

Subjek II RM: Jadi menurut Subjek II tentang pengucapan talak tiga sekaligus pandangan Ibnu Timiyah ialah melihat faktor penyebab sebab serta lihat situasi dan kondisi yang bersangkutan apakah dia karena marah atau emosi, dan karena lbnu Taimiyah juga tidak terlepas dari nash-nash Al-quran dan Hadis. istinbath hukum dan ketentuan yang dijadikan dasar sebagaimana dalam Alquran dan sunah-sunah nabi dan juga tidak terlepas dari undang undang negara dan Kompilasi Hukum Islam(KHI) yang menetapkan keputusan itu.

Menurut Subjek III ASL tentang pengucapan talak tiga sekaligus pandangan Ibnu Taimiyah bahwa talak tersebut tetap jatuh satu walaupun dalam satu kali ucap karena talak tiga itu tidak main-main dan sudah jelas dalam Al-quran talak itu melalui proses bertahap tidak hanya satu waktu. bahwa istinbath hukum dan ketentuan yang dijadikan dasar sebagaimana dalam Al-quran surah Al-Baqarah: 229 bahwa talak itu ada satu dua dan tiga melauli proses danhadisnabi sama saja hanya saja setiap ulama berbeda dalam menafsirkan hadis 
Menurut SS Subjek IV tentang pengucapan talak tiga sekaligus pandangan Ibnu taimiyah bahwa dia sangat sepakat dengan pendapat Ibnu Timiyah karena bagaimana pun juga talak itu ditentukan oleh situasi dan kondisi jadi tidak bisa jatuh tiga ketika mengucapkannya dalam satu waktu. bahwa istinbath hukum dan ketentuan yang dijadikan dasar sebagaimana dalam Al-quran dan Hadis. Hadis yang dipakai Muhammmadiyah pun yang lebih kuat atau yang shahih.

Menurut NM Subjek $\mathrm{V}$ tentang pengucapan talak tiga sekaligus pandangan Ibnu taimiyah bahwa dia sependapat dengan Ibnu Timiyah karena bagaimana pun juga talak itu ditentukan oleh situasi dan kondisi jadi tidak bisa jatuh tiga ketika mengucapkannya dalam satu waktu kalaupun jatuh itupun jatuh talak satu, dan bahwa istinbath hukum dan ketentuan yang dijadikan dasar sebagaimana dalam Al-Quran surah Al-Baqarah ayat: 229 bahwa talak itu ada talak satu, dua dan tiga tahapan dan jarak, dan hadist yang dipakai Muhammmadiyah pun yang lebih kuat atau yang shahih.

\section{Relevansi pengucapan talak tiga sekaligus dengan zaman sekarang.}

bahwa talak tiga sekaligus memang dari dulu sejak zaman Rasulullah sudah ada dan sampai sekarang talak masih menjadi pro dan kontra, ada juga seseorang dengan mengucapkantalak tersebut berlaku tiga tetapi ada pula yang mengutarakan berlaku satu dan masing masing punya argumen dan penguat untuk menentukan status hukumnya. Apabila melihat kembali pemikiran lbnu Taimiyah khususnya tentang pengucapan talak tiga secara sekaligus diatas, tampaknya pemikiran yang dilontarkannya ini bukan persoalan yang baru ia hanya mengemukakan dan menguatkan kembali pemikiran-pemikiran para pakar hukum Islam (fiqih) terdahulu (salaf) untuk diterapkan pada zamannya. Lahirnya pemikiran lbnu Taimiyah tidak lain hanya untuk mengembalikan parktik fiqih masyarakat muslim keajaran murni Islam aitu sesuai dengan $\mathrm{Al}$-quran dan Hadits, merelevansikan pemikiran Ibnu Taimiyah dengan zaman sekarang tampaknya merelevansikan pula dalil-dalil Al-quran atau sunnah yang digunakan Ibnu Taimiyah. Bahkan pada esensinya upaya yang dialakukan pada bahasan ini adalah merelevansikan dalili-dalil tersebut tapi ada satu hal yang perlu disandari bahwa kalau orang sudah melaksanakan pernikahan maka dia harus berusaha menjaga betul agar senantiasa bisa bersatu nah karena itu bermain main dengan kata kata talak dan bisa cerai, jangan sampai muncul atau diusahakan semaksimal mungkin tidak boleh terjadi apapun alasannya hendaklah dituntut kesabaran, oleh karena itu kalau terjadi kata kata cerai dan pisah itu maka konsekuensinya perceraian itu sudah jatuh dan tidak ditemukan lagi pada zaman sekarang adanya kemaslahatan untuk masyarakat muslim yang menjatuhkan talak tiga secara sekaligus dan dijatuhkan pula talak tersebut sebanyak talak tiga. Justru dengan talak tiga sekaligus itu, mendatangkan kemudharatan bagi keluarga masyarakat muslim.

Hal ini disebabkan, dengan adanya talak tiga terlebih lagi diucapkan secara sekaligus itu menjadikan masyarakat muslim tidak dapat memperbaiki kembali rumah tangganya yang pernah hancur, karena pasangan suami dalam masyarakat muslim tidak bisa mengadakan akad baru menunggu bekas istrinya tersebut kembali melakukan perkawinan dengan orang lain. Dalam perihal ini pun diantara mereka harus ada melakukan hubungan dan baru kemudian apabila tidak terdapat kecocokan mereka bercerai tanpa adanya paksaan atau permintaan dari suami pertama.

Dengan demikian dapat pula dikatakan bahwa pemikiran ulama Muhammadiyah yang menyatakan bahwa orang yang menjatuhkan talak tiga hanya dihitung talak satu masih dan lebih relevan untuk kondisi masyarakat muslim didunia islam. Akan tetapi untuk relevansi dengan kondisi sekarang dipertimbangkan kembali melalui perumusan Undang-Undang Hukum Positif Islam yaitu berlakunya aturan yang disahkan di negara Indonesia bahwa perceraian hanya bisa dilaksanakan di depan 
hakim dan persidangan pada Pengadilan Agama yang sudah ada dalam UndangUndang yang telah diatur pada Bab XVI dalam Pasal II5: "Perceraian akan berlaku dihadapan persidangan Pengadilan Agama dengan alasan Hakim sudah semaksimal mungkin belum belumberhasil membujuk antara laki-laki dan perempuan agar tidak melakukan perceraian.Kemudian Pasal 123: "perceraian itu terjadi terhitung pada saat perceraian itu dinyatakan didepan sidang pengadilan". Pemikiran-pemikiran para pakar hukum Islam terdahulu memang patut dihargai dan dihormati walapun di Indonesia saat ini menggunakan Kompilasi Hukum Islam (KHI) sebagaimana kaidah Fiqih menyatakan:

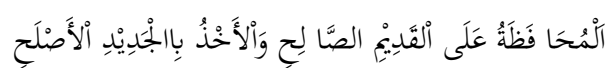

"menghormatil memelihara pendapat salafussalih yang dulu dan kita mancari pendapat baru yang lebih baik."

Sebagaimana dalam kaidah tersebut mengingatkan kepada umat Islam khususnya untuk selalu menghormati dan menghargai pendapat-pendapat salafus salih terdahulu walaupun sudah beda zaman tempat sekarang dan waktu dimana kita berpijak di situlah kita mengikuti aturan hukum di wilayah itu.

Setelah melakukan wawancara dan mendapatkan data dari hasil penelitian yang dilaksanakan tentang pengucapan talak tiga sekaligus menurut persepsi ulama Muhammadiyah. Sudah terlihat dari pendapat-pendapat yang disampaikan oleh para subjek penelitian. Pendapat para subjek tentang pengucapan talak tiga sekaligus dari ke 5 subjek tersebut mereka setuju menyatakan bahwa pengucapan talak tiga sekaligus pandangan Ibnu Taimiyah yang mengatakan talak itu tetap jatuh satu dan itu tidak bisa langsung tiga kalau pun ada itu haya jatuh satu dan alasan yang sama bahwa terdapat didalam Al-Quran surat Al-Baqarah: 229 sudah jelas bahwa talak itu ada proses tahapan, jarak dan waktu. Selain itu juga bahwa adanya proses tersebut untuk membuka peluang rujuk kembali bagi sisuami dan istri biar tidak terjadi perceraian karena perpisahan dalam rumah tangga merupakan hal yang sangat tidak disukai oleh Tuhan yang maha kuasa. Oleh sebab itu menurut Ibnu Taimiyah Allah sebenarnya tidak mensyari'atkan bagi seseorang untuk menjatuhkan talak tiga secara sekaligus.

Namun perceraian yang ada di Indonesia saat ini hanya bisa dikatakan jatuh talak dihadapan majelis hakim sidang di Peradilan Agama dan terdapat pada UndangUndang Kompilasi Hukum Islam (KHI) di Indonesia. Tentuya segala perkara perceraian hanya bisa dikatakan cerai apabila sudah melalui sidang Pengadilan Agama. Oleh karena itu, kepada pihak yang berwenang terutama majelis hakim Peradilan Agama di Indonesia sebagai seorang pemimpin yang mestinya memutuskan segala perkara yang menjadi wewenangnya dengan penuh dan memperhatikan serta melindungi kemaslahatan orang-orang yang berperkara dalam hal ini kasus talak tiga hendaknya dianggap satu kali talak, karena dengan menjatuhkan talak satu dipastikan adanya kemaslahatan yang banyak didalamnya sekaligus menolak kemudharatan. Beradasarkan hal ini, maka pengucapan talak sekaligus dipandang tidak jatuh dan hanya jatuh talak satu perlu kembali dikonsultasikan kepada salah satu kaidah Fiqhiyyah yaitu:

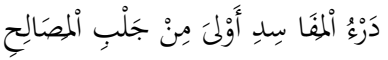

"Menolak berbagai kerusakan lebih utama (lebih didahulukan) dari pada mengambil berbagai kemaslahatan."

$\begin{array}{ccr} & \text { Peradilan agama dipandang penting } \\ \text { untuk } & \text { memperhatikan dan }\end{array}$ mempertimbangkanserta membandingkan antara kemaslahatan dan kemudharatan tersebut, karena hal ini adalah sebagai kewajiban peradilan agama.Penulis menyerukan agar masyarakat muslim yang mampu dan terlebih lagi para ulama agar tidak menampakkan sikap fanatik tersebut, justru sebenarnya yang diinginkanadalah agar masyarakat tersebut mengkaji kesumber islam yaitu Al-quran dan sunnah. Ayat diatas sebenarnya telah menyatakan sebenarnya bahwa agama Islam selalu berkomunikasi pada setiap perbedaan zaman dan perkembangan pemikiran manusia 
sebagaimana dalam Qawaidul Fighiyyah (kaidah Fiqih) yaitu:

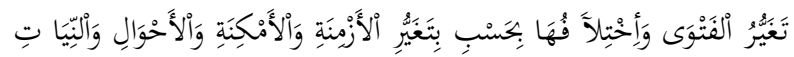

$$
\text { وَالْعَا يُدِ }
$$

"Perubahan suatu fatwa dan perbedaannya tergantung dengan perubahan zaman, tempat, keadaan, niat dan kebiasaan."

Kendati Islam menerima segala perubahan karena semua itu adalah untuk memberikan kemudahan kepada umat manusia namun dengan kemudahan dan dengan alasan perubahan zaman tersebut bukan berdasarkan hawa nafsu. Tetapi tujuan utama dari kemudahan kemudahan yang sebenarnya sesuai dengan tuntutan Al-quran serta bertujuan untuk mewujudkan kemaslahatan untuk seluruh umat manusia yang meyakini Islam sebagai agamanya.

\section{Penutup}

Dari hasil penelitian yang sudah dilaksanakan oleh penulis, dalam hal ini dapat ditarik kesimpulan bahwa dalam penelitian ini adalah ulama Muhammadiyah Palangka Raya sepakat dengan Ibnu Taimiyah yang berpendapat bahwa talak tiga secara langsung sekali ucap hukumnya tidak sah dan tetap dipandang berlaku talak I (satu). Persepsi tersebut bersandar kepada Alquran dan hadits, para sahabat dan Tabi'in baik salaf maupun khalaf, dan juga bisa memberikan peluang terhadap silaki-laki dan perempuan agar rujuk lagi. karena mengambil kemaslahatan lebih baik dari pada mengambill kemudharatan.Menurut ulama uhammadiyah talak yang disyari'atkan pada hukum islam adalah talak raj'i atau talak yang boleh ubtuk rujuk kembali yang terdapat pada perceraian untuk pertama kali sejalur dalam Al-quran surat Al-Baqarah:229 serta dalam hadits. Bahwa talak tidak bisa jatuh tiga dalam satu kali ucapan atau satu waktu. Pandangan ulama Muhammadiyah ini dipandang relevan dengan zaman sekarang. Pendapat seperti ini sebenarnya untuk menghindari kemudharatan yang lebih besar dan tentunya akan merugikan kedua belah pihak baik mantan suami maupun istri. Dipandangnya talak tiga sekaligus sebagai talak satu, tentunya juga mendatangkan manfaat yang besar pula agar mereka masih memiliki kesempatan supaya dapat rujuk dan memperbaiki rumah tangganya yang sempat hancur serta mereka pun dapat introspeksi diri demi kebaikan dan kelestarian rumah tangganya. Karena perkara cerai dobolehkan tetapi sangat tidak disukai oleh Allah SWT.

\section{Daftar Pustaka}

Kementerian Agama RI,Al-Quran dan

Terjemahannya,(Jakarta:

LenteraAbadi) 2010.

Al-jauziyyah, Ibn Qayyi I'lam al-Muawaqqi'in 'an Rabb al-'alamin,(Kairo: Dar alHadist),2002.

Asy-SyarbiniMuhammad Khatib,Mugni alMuhtaj, (Beirut: DarulFikr, 2003), juz 3

Abidin, Slamet.,FiqihMuhakahat II.(Bandung: PustakaSetia), 1999.

Al- Asqalany, IbnuHajar, Kitab BulughulMaram, tt.

Al- Kautsary Muhammad zahid "al-IsfaqAlAhkami At-Thalaq”,(Maktabah Majallah al-Islam)tt.

Ariyadi, Ariyadi. "Metodologi Istinbath Hukum Prof. Dr. Wahbah Az Zuhaili." Iurnal Hadratul Madaniyah 4.I (2017): 32-39.

Ariyadi, Ariyadi. "Tindak Pidana Pelaku Eksploitasi Seksual Pada Anak Di Tinjau Dari Hukum Positif." /urnal Hadratul Madaniyah 5.2 (20I8): 73-88.

Ariyadi, Ariyadi. "Tindak Pidana Pelaku Eksploitasi Seksual pada Anak Menurut Hukum Islam." Jurnal Hadratul Madaniyah 6.I (2019): 43-67.

AyyubHasan, FiqihKeluarga Islam,cet. V, (Jakarta: Pustaka al-Kautsar),2006.

Daud Abu, Buku SunanAbiDawud, Hadistke 2164, VI, (Dar al-Fikr), I 984

An-Nawawi Imam, SyarahSahih Muslim, Jakarta: PustakaAzzam, 20I I

AlhafidzAhsin W, Figh Islam, (Jakarta: Amzah),2013.

GhozaliRahmanAbdul, FiqihMunakahat, (Jakarta: Kencana),2003

Ilham, MM, KBBI Indonesia, Mitra Jaya: Juni 2010

KamalMalik Abu, FikihWanita. (Jakarta: Pena PundiAksara,) 2007 
Muslim Abi Husain ibn An-Naisaburi, Shahih Muslim, Semarang-Indonesia: Toha Putra, tt,

Muslimah, dkk., Cara Munah MembuatProposal Penelitian, Palangka Raya: Narasi Nara, 2020.

Norcahyono, Norcahyono, and Ariyadi Ariyadi. "Pandangan Majlis Tarjih Muhammadiyah Kalimantan Tengah Tentang Tindakan Euthanasia Dalam Pendidikan Waris Islam." Tunas: Jurnal Pendidikan Guru Sekolah Dasar 5.I (2019): 50-6I.

Rahmanto, TalakTiga Sekaligus Dalam Perspektif Ibnu Taimiyah, Palangka Raya, 2009

UlfahRahmaniah, Nikah masa idah talak raj'i dikecamatan Pahandut, Palangka Raya, 2003

SabiqSayyid, FiqihSunnah, Jakarta: P.T Pena PundiAksara, 2009

SusetyaWawan, MerajutBenangCintaPerkawinan, Jakarta: Republika, 2009

Syihab Muhammad Quraisy, Tafsir al-Misbah, (Jakarta: LenteraHati), 2000

Zuhaili Wahbah Ushul Fiqih, juz I,

Damaskus-Suriah: Dar al-Fikr, 200I 